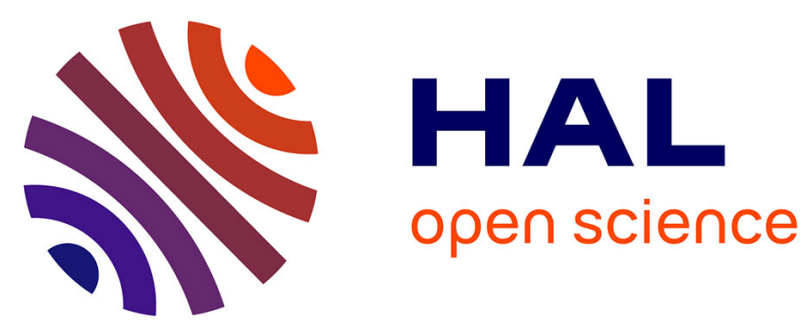

\title{
Damages induced by heavy ions in titanium silicon carbide: effects of nuclear and electronic interactions at room temperature
}

\author{
Jean-Christophe Nappé, Philippe Grosseau, F. Audubert, Bernard Guilhot, \\ Michel Beauvy, Mourad Benabdesselam, Isabelle Monnet
}

\section{To cite this version:}

Jean-Christophe Nappé, Philippe Grosseau, F. Audubert, Bernard Guilhot, Michel Beauvy, et al.. Damages induced by heavy ions in titanium silicon carbide: effects of nuclear and electronic interactions at room temperature. Journal of Nuclear Materials, 2009, 385 (2), pp.304-307. 10.1016/j.jnucmat.2008.12.018 . hal-00408936

\section{HAL Id: hal-00408936 https://hal.science/hal-00408936}

Submitted on 4 Aug 2009

HAL is a multi-disciplinary open access archive for the deposit and dissemination of scientific research documents, whether they are published or not. The documents may come from teaching and research institutions in France or abroad, or from public or private research centers.
L'archive ouverte pluridisciplinaire HAL, est destinée au dépôt et à la diffusion de documents scientifiques de niveau recherche, publiés ou non, émanant des établissements d'enseignement et de recherche français ou étrangers, des laboratoires publics ou privés. 


\title{
Damages induced by heavy ions in titanium silicon carbide: effects of nuclear and electronic interactions at room temperature
}

\author{
J.C. Nappée, ${ }^{\mathrm{a},}$, Ph. Grosseau ${ }^{\mathrm{a}}$, F. Audubert ${ }^{\mathrm{b}}$, B. Guilhot ${ }^{\mathrm{c}}$, M. Beauvy ${ }^{\mathrm{b}}$, M. Benabdesselam ${ }^{\mathrm{d}}, \mathrm{I}_{\text {. Monnet }}^{\mathrm{e}}$ \\ ${ }^{a}$ École Nationale Supérieure des Mines, SPIN/PMMC, LPMG UMR CNRS 5148, 158 cours Fauriel, 42023 Saint- \\ Étienne cedex 2, France \\ ${ }^{b}$ CEA, DEN, DEC/SPUA/LTEC, Cadarache, 13108 St Paul lez Durance, France \\ ${ }^{c}$ École Nationale Supérieure des Mines, Centre CIS, 158 cours Fauriel, 42023 Saint-Étienne cedex 2, France \\ ${ }^{d}$ Université de Nice - Sophia Antipolis, LPMC UMR CNRS 6622, Parc Valrose, 06108 Nice cedex 2, France \\ ${ }^{e}$ GANIL/CIMAP/CIRIL, bd. Henri Becquerel, BP 55027, 14076 Caen cedex 5, France
}

\begin{abstract}
Thanks to their refractoriness, carbides are sensed as fuel coating for the $\mathrm{IV}^{\text {th }}$ generation of reactors. Among those studied, the $\mathrm{Ti}_{3} \mathrm{SiC}_{2}$ ternary compound can be distinguished for its noteworthy mechanical properties: the nanolamellar structure imparts to this material some softness as well as better toughness than other classical carbides such as SiC or TiC. However, under irradiation, its behaviour is still unknown. In order to understand this behaviour, specimens were irradiated with heavy ions of different energies, then characterised. The choice of energies used allowed separation of the effects of nuclear interactions from those of electronic ones.
\end{abstract}

Key words : $\mathrm{Ti}_{3} \mathrm{SiC}_{2}$, irradiation, heavy ions, nuclear collisions, electronic interactions

PACS : 61.82.-d, 61.80.Jh, 25.75.Ag, 34.50.Bw

\section{Introduction}

As part of Generation IV International Forum (GIF), new systems are studied, from the point of view of the reactor as well as the fuel cycle. These systems are characterised by an increased security level, better economic competitiveness, and an ability to recycle all the fuel in order to upgrade to a fissionable material and minimize longlived waste production by transmutation. Among the six systems considered by the GIF, the Gas Fast Reactor (GFR) is studied in France; it is designed to work under helium-pressure and high-temperature (1100-1300 K).

These working conditions led to the selection of non-oxide refractory ceramics as fuel coating. Thus, carbides turn out to be great candidates thanks to their remarkable mechanical and thermal properties. However, their behaviour under irradiation has to be studied in more details.

Among the studied carbides, the ternary $\mathrm{Ti}_{3} \mathrm{SiC}_{2}$ presents some interesting prospects. Indeed, in $1972 \mathrm{Nickl}$ et al. [1] remarked that this material, which was synthesized for the first time by a Viennese group in 1967 [2], is abnormally soft for a carbide. At the beginning of the '90s, Pampuch et al. [3,4] and Lis et al. [5-7] led works on the pure bulk $\mathrm{Ti}_{3} \mathrm{SiC}_{2}$ synthesis; their best results were compounds with 80-90\% purity, impurities being $\mathrm{TiC}_{\mathrm{x}}$ and $\mathrm{TiSi}_{2}$. During their works, they demonstrated that this material is both stiff (Young's modulus of $325 \mathrm{GPa}$ ) and soft (Vickers hardness of $6 \mathrm{GPa}$ ). Moreover, like Goto et al. [8] some years before, they noted that the hardness of this carbide decreases as the applied load increases; this property led them to qualify $\mathrm{Ti}_{3} \mathrm{SiC}_{2}$ as a "ductile ceramic".

At the end of the '90s, Barsoum et al. [9-14] intensively studied this material as well as other ceramics with similar properties. In 2000 [15], they brought all these compounds together within one family of nanolamellar materials, named MAX Phases, of general formula $\mathrm{M}_{n+1} \mathrm{AX}_{n}$ where $n=\{1,2,3\}, \mathrm{M}$ is an early transition metal, A is an A-group (mostly IIIA and IVA) element, and $\mathrm{X}$ is $\mathrm{C}$ and/or N. Materials of this family are unusual in that they combine some properties of metals with those generally attributed to ceramics; thus, these materials are stiff, thermal and electrical conductors, readily machinable with tools for steels, andrelatively soft and tough. More specifically, $\mathrm{Ti}_{3} \mathrm{SiC}_{2}$ is stable under inert atmosphere or vacuum up to $1975 \mathrm{~K}[9,13,16]$, resistant to quenching from $1475 \mathrm{~K}$ to room temperature [9,17], has a thermal conductivity of $37 \mathrm{~W} \mathrm{~m}^{-1} \mathrm{~K}^{-1}$ at room temperature and $32 \mathrm{~W} \mathrm{~m}^{-1} \mathrm{~K}^{-1}$ at $1775 \mathrm{~K}$ [13], a toughness of $9 \mathrm{MPa}^{1 / 2}$ $[15,18]$, a brittle-ductile mechanical transition as a function of temperature and strain rate [9,19-21], an electrical conductivity of $4.5 \times 10^{6} \Omega^{-1} \mathrm{~m}^{-1}[9,15,22,23]$, and good corrosion resistance in common acids and $\mathrm{NaOH}$ (corrosion rate $<300 \mu \mathrm{m} \mathrm{a}^{-1}$ in $\mathrm{HNO}_{3}$, the worst case) [24-26]. Nevertheless, no information is available about its behaviour under irradiation.

Therefore, the aim of this study is a better knowledge of the behaviour under irradiation of $\mathrm{Ti}_{3} \mathrm{SiC}_{2}$, whose otherwise outstanding properties allow its consideration it as a cladding material for future fuels.

\section{Experimental}

The studied material is a polycrystalline commercial compound provided by 3-ONE-2 (Voorhees, NJ, USA). An estimation of the secondary phase proportion in the as-received material was carried out by X-Ray Diffraction (XRD); the samples consist of about $80 \% \mathrm{Ti}_{3} \mathrm{SiC}_{2}, 15 \% \mathrm{TiC}_{\mathrm{x}}$, and $5 \% \mathrm{TiSi}_{2}$. Figure 1 shows the surface state of the as-polished specimens through Atomic Force Microscopy (AFM); the lower hardness of $\mathrm{Ti}_{3} \mathrm{SiC}_{2}$ compared with the $\mathrm{TiC}_{\mathrm{x}}$ and $\mathrm{TiSi}_{2}$

* Corresponding author. Tel.: +33 477420 213; fax: +33 477499694.

E-mail: nappe@emse.fr. 
phases can be noted.

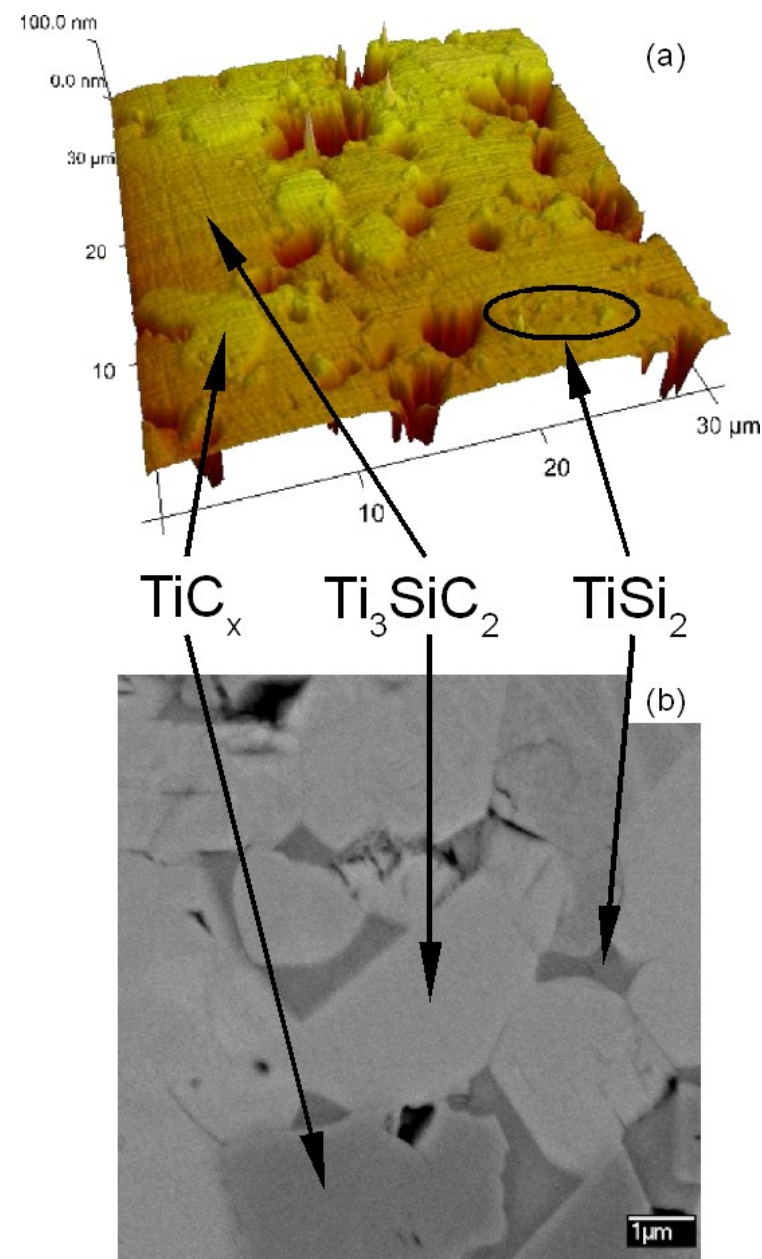

Fig. 1: Surface of as-polished $\mathrm{Ti}_{3} \mathrm{SiC}_{2}$ by AFM (a) and back-scattered electrons FEG-SEM (b)

The as-received specimens were polished with diamond suspensions down to $1 \mu \mathrm{m}$. They were subsequently irradiated at room temperature with heavy ions. This kind of irradiation aims to simulate the interactions present in reactors (impacts of fission products, recoil atoms of alpha-decays, and neutrons) without the drawback of activating the specimens.

When heavy ions penetrate through a solid, they get decelerated via two different processes, namely, elastic collisions with target nuclei (with nuclear stopping power $S_{n}$ ) and inelastic collisions with target electrons (with electronic stopping power $S_{e}$ ). In order to understand the effects of both nuclear and electronic interactions on $\mathrm{Ti}_{3} \mathrm{SiC}_{2}$, two runs of irradiation were performed. The first one, called "low energy irradiation", was achieved with the $4 \mathrm{MeV} \mathrm{Au}$ ions of the ARAMIS accelerator at the CSNSM of Orsay (France) to gain the nuclear interactions effects. The second one, named "high energy irradiation", was made with the $90 \mathrm{MeV}$ Xe ions delivered by the IRRSUD accelerator at the GANIL to understand the electronic interactions influence. Each run was carried out for 4 ion fluences: $10^{12}, 10^{13}, 10^{14}$, and $10^{15} \mathrm{~cm}^{-2}$. The depths of the damaged zone were determined aided by the TRIM code [27].

To characterise surface modifications to the samples, two microscopic methods were used: Field Emission Gun Scanning Electron Microscopy (FEG-SEM) and AFM. The structure of the irradiated zone was analysed by Low Incidence XRD (LI-XRD) technique.

\section{Results}

The low energy irradiation spoils the first $500 \mathrm{~nm}$ of $\mathrm{Ti}_{3} \mathrm{SiC}_{2}$ essentially by nuclear interactions. By microscopic means, modifications are noticeable from a fluence of $10^{15} \mathrm{~cm}^{-2}$. By FEG-SEM (Fig. 2), at some places it was noted that the $\mathrm{Ti}_{3} \mathrm{SiC}_{2}$ grain boundaries were eroded. This could be the consequence of preferential sputtering due to a weaker displacement threshold energy of the atoms in grain boundaries than inside the grains. By AFM, surface etching can be observed; it may be explained by preferential sputtering as a function of the $\mathrm{Ti}_{3} \mathrm{SiC}_{2}$ crystallite orientation. In fact, orientation of the basal planes of the $\mathrm{Ti}_{3} \mathrm{SiC}_{2}$ hexagonal close-packed structure perpendicularly to the ion beam would lower the ion channeling effects inside the lattice, and so would increase the sputtering yield; therefore, as a function of the crystallite orientation, the sputtering yield would vary and so lead to this kind of microstructure. However, the as- 
irradiated surface is too spoiled to differentiate the three phases.
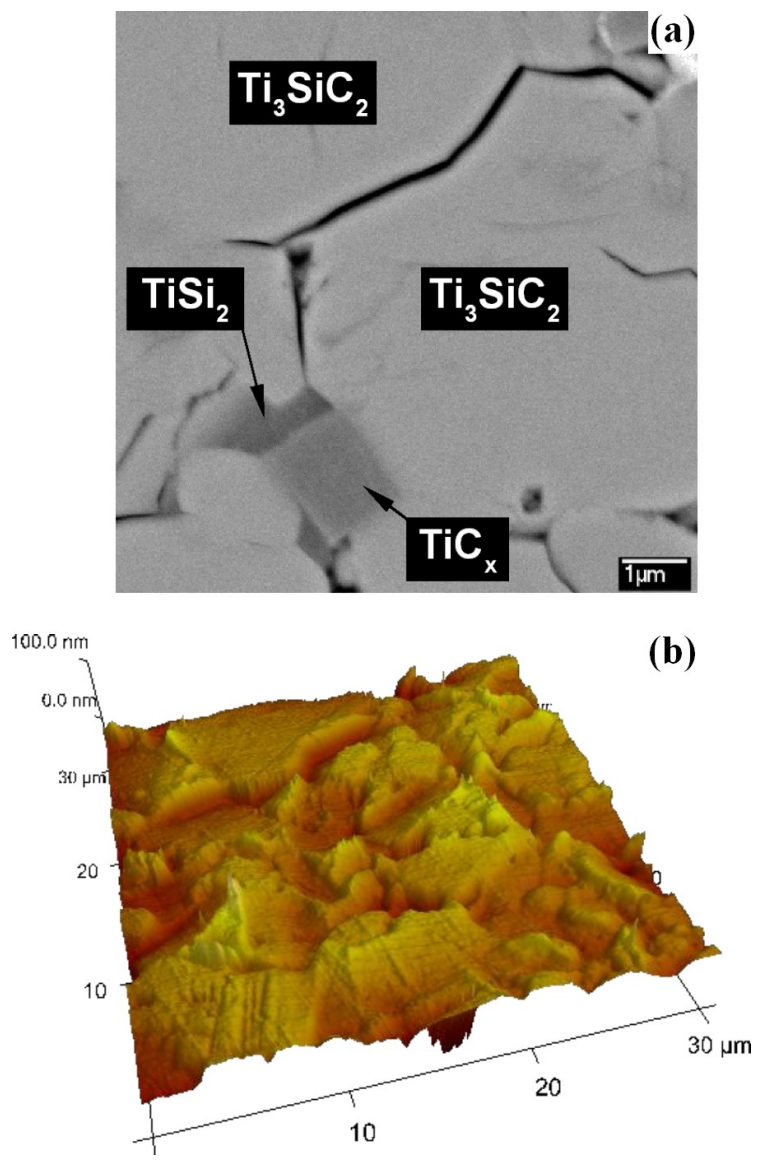

Fig. 2: Surface of $\mathrm{Ti}_{3} \mathrm{SiC}_{2}$ after Au (4 MeV) irradiation at a fluence of $10^{15} \mathrm{~cm}^{-2}$ by FEG-SEM (a) and AFM (b)

For the low energy irradiation, XRD was achieved under a $1^{\circ}$ incidence angle (Fig.3), which corresponds to an Xray penetration of $230 \mathrm{~nm}$ in $\mathrm{Ti}_{3} \mathrm{SiC}_{2}$; $\mathrm{Al}$ peaks are from a mask intentionally layed on the virgin part of the samples during measurements. It brings out both a decrease of the peak intensity of the three phases as a function of the Au fluence from $10^{14} \mathrm{~cm}^{-2}$, and an increase of the baseline. These diffractogram changes are certainly due to a partial amorphisation of the material due to nuclear collisions. Indeed, this phenomenon was often encountered during irradiation of other materials such as $\mathrm{SiC}$ [28] or some oxides [29].

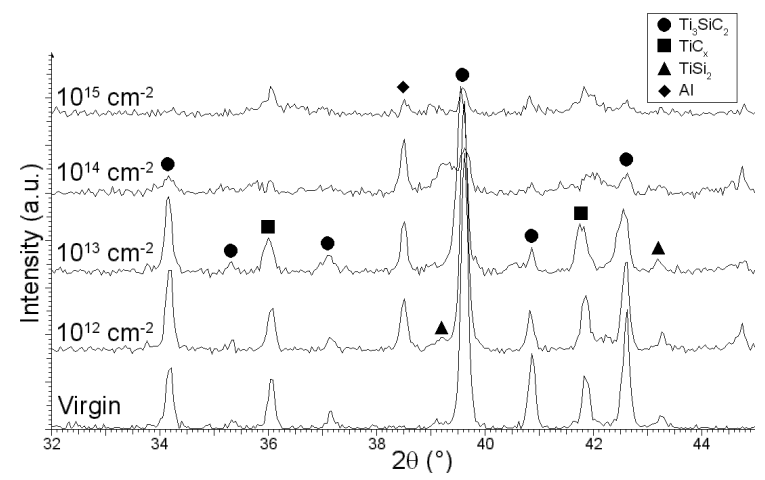

Fig. 3: XRD patterns of Au irradiated samples

The high energy irradiation damages the first $5 \mu \mathrm{m}$ of $\mathrm{Ti}_{3} \mathrm{SiC}_{2}$ by electronic interactions. Through FEG-SEM and AFM, two phenomena are revealed from Xe fluence of $10^{15} \mathrm{~cm}^{-2}$ fluence (Fig. 4):

- A surface etching due to differente behaviour under irradiation of the phases present; the identification of the phases was performed by Energy Dispersive X-ray spectroscopy.

- The appearance of "hills" on the $\mathrm{Ti}_{3} \mathrm{SiC}_{2}$ surface: their diameter varies from 50 to $100 \mathrm{~nm}$, with a height of around $10 \mathrm{~nm}$, and an estimated density of about $(1.0-1.5) \times 10^{10} \mathrm{~cm}^{-2}$. 

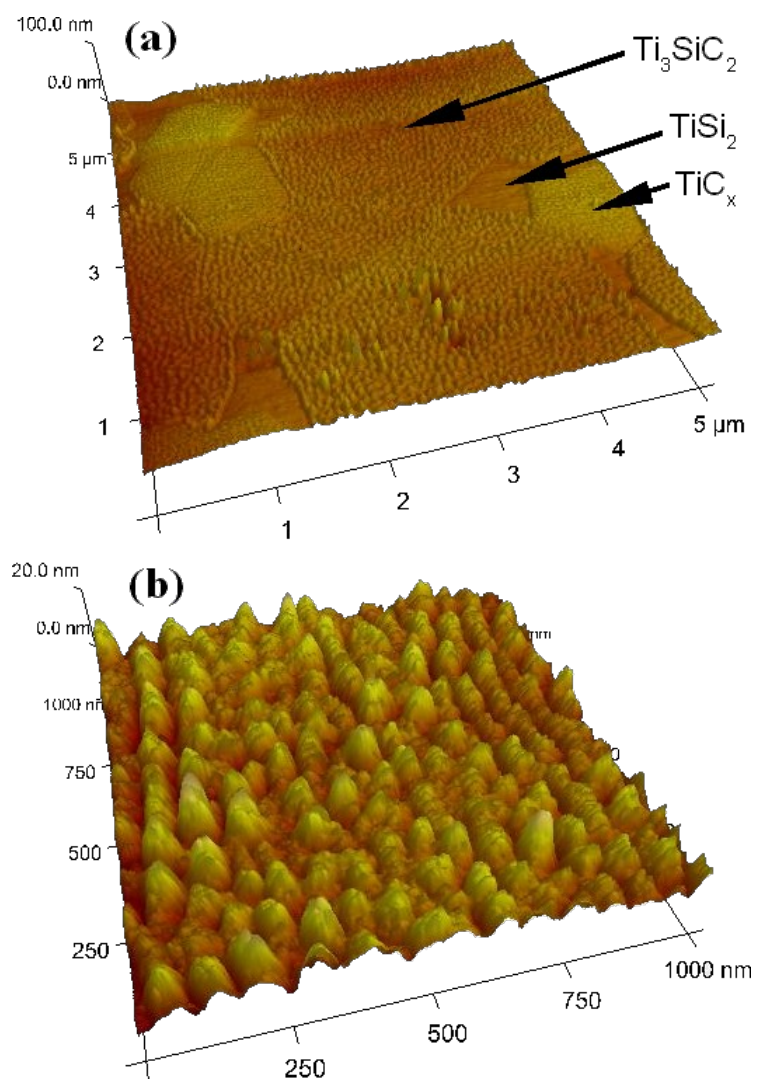

Fig. 4: Surface of $\mathrm{Ti}_{3} \mathrm{SiC}_{2}$ after $\mathrm{Xe}(90 \mathrm{MeV})$ irradiation at a fluence of $10^{15} \mathrm{~cm}^{-2} \mathrm{AFM}$; (a) $5 \mathrm{x} 5 \mu \mathrm{m}^{2}$ scan and (b) $1 \mathrm{x} 1$ $\mu \mathrm{m}^{2}$ scan of the $\mathrm{Ti}_{3} \mathrm{SiC}_{2}$ phase

The XRD analysis was realised under a $3^{\circ}$ incidence angle (Fig. 5), which corresponds to an X-ray penetration depth of $720 \mathrm{~nm}$ in $\mathrm{Ti}_{3} \mathrm{SiC}_{2}$. Diffraction patterns also reveal an amorphisation phenomenon, but only for $\mathrm{Ti}_{3} \mathrm{SiC}_{2}$ phase. Moreover, we can notice a modification of the unit cell of this compound; the peak initially located at $40.9^{\circ}$, relative to the (001) diffraction planes, is shifted to lower $2 \theta$ as a function of the fluence. Estimating the parameters of the unit cell as a function of the fluence (Fig. 6), an expansion of the unit cell along the $c$ axis without significant variation of the unit volume may be underlined.

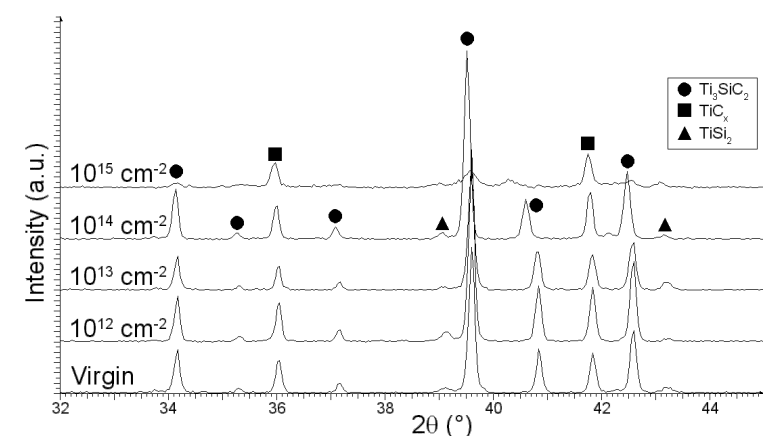

Fig. 5: XRD patterns of Xe irradiated samples 


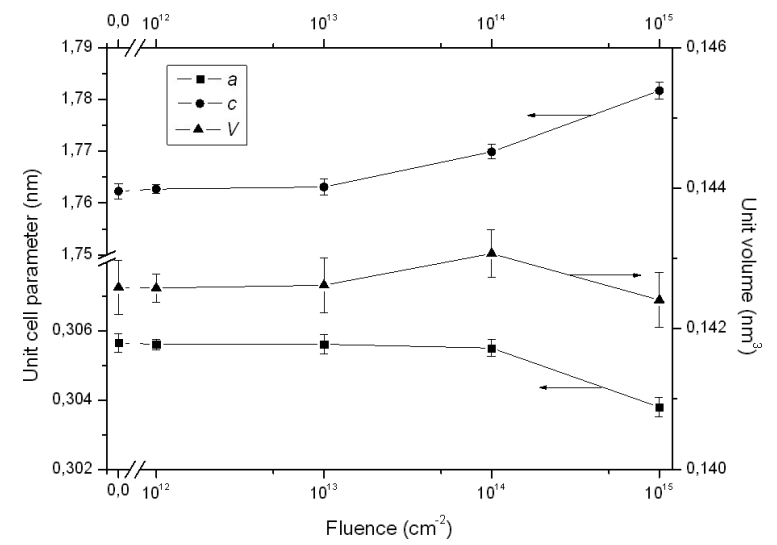

Fig. 6: $\mathrm{Ti}_{3} \mathrm{SiC}_{2}$ unit cell parameters as a function of the Xe irradiation fluence; lines are only to guide the eye

\section{Discussion}

Whereas the phenomena due to nuclear interactions can be understood through the elastic collisions during a low energy irradiation, those due to electronic interactions are often misunderstood. This discussion allows to brighten these phenomena.

The phenomenon of the appearance of "hills" was apparently not yet observed in other materials for these conditions (energies of about $100 \mathrm{MeV}$ and ion fluences close to $10^{15} \mathrm{~cm}^{-2}$ ). Indeed, numerous authors remarked bumps during irradiations with similar energies, but generally fluences do not exceed some $10^{12} \mathrm{~cm}^{-2}$ [30-36]; thus they noted the same number of hills as of incident ions. In this case, authors usually attribute their appearance to the thermal spike model. The swift heavy ions lose energy during a short time $\left(<10^{-16} \mathrm{~s}\right)$ inside a cylindrical zone around the ion trajectory. When $S_{e}$ is higher than $S_{\text {eth }}$ (threshold electronic stopping power), melting of the cylindrical zone followed by cooling and resolidification lead to the formation of amorphous tracks inside the material. This phenomenon, which is more important at the near surface (where $S_{e}$ is maximum), leads to high stresses and strains that would result in a flow of matter to form one hill by each ion. Only one paper notes about bumps for fluences higher than some $10^{12} \mathrm{~cm}^{-2}$ [34]; they noticed hills from lower fluence up to $2 \times 10^{14} \mathrm{~cm}^{-2}$ and explained this by an agglomeration of the hills formed by thermal spikes. Nevertheless these explanations are not valid in our case: first, the density of hills is about $10^{5}$ lower than the fluence, so thermal spikes cannot account for the bumps; second, this type of relief are only noted from $10^{15} \mathrm{~cm}^{-2}$ (not at lower fluences), so bumps are not due to agglomeration.

Other authors observed the same type of relief for very low energy ions (a few keV) at higher fluences (greater than $\left.10^{16} \mathrm{~cm}^{-2}\right)$. In this case, the surface morphology would depend on both ion erosion and surface diffusion processes [37]. Other authors interpret this type of relief as the agglomeration of the projected ions at the very near surface of the target, implying the formation of nanobubbles [38] or nanoparticles [39]. Whatever the explanation, our fluences are too weak to allow the formation of $50-100 \mathrm{~nm}$ hills.

Defects noticed by LI-XRD are also not yet entirely understood. Amorphisation can be explained by several processes such as the formation of amorphous tracks by thermal spikes, irradiation induced microstrains in the unit cell, or a drop-off of the crystallite size. Irradiation induced microstrains seem to be an appropriate explanation since an expansion of the unit cell was also noted for $\mathrm{Ti}_{3} \mathrm{SiC}_{2}$.

In order to better understand these electronic interaction-induced phenomena, an in-depth study of the diffraction patterns is in progress. Observation of cross-sections by Transmission Electron Microscopy will also be performed.

\section{Conclusion}

This first study about damages induced by heavy ions in $\mathrm{Ti}_{3} \mathrm{SiC}_{2}$ at room temperature allows distinction between the effects of nuclear and electronic interactions on this remarkable ceramic. Elastic collisions lead to the amorphisation of all the phases of the specimens, sputtering of the $\mathrm{Ti}_{3} \mathrm{SiC}_{2}$ grain boundaries, and preferential sputtering as a function of the crystallite orientation. On the other hand, electronic interactions induce the amorphisation of only $\mathrm{Ti}_{3} \mathrm{SiC}_{2}$, expansion of the $\mathrm{Ti}_{3} \mathrm{SiC}_{2}$ unit cell along the $c$ axis, and the formation of "hills", the latter of which remains misunderstood yet.

\section{Acknowledgment}

The authors would like to gratefully thank Lionel Thomé (CSNSM) for their great help during the irradiation experiments. This work was partly supported by the French research group MATINEX.

\section{References}

[1] J.J. Nickl, K.K. Schweitzer, P. Luxenberg, J. Less-Common Metals, 26 (1972) 335-353.

[2] W. Jeitschko, H. Nowotny, Monatsh. Chem., 98 (1967) 329-337. 
[3] R. Pampuch, J. Lis, L. Stobierski, M. Tymkiewicz, J. Eur. Ceram. Soc., 5 (1989) 283.

[4] R. Pampuch, J. Lis, J. Piekarczyk, L. Stobierski, J. Mater. Synth. Process., 1 (1993) 93.

[5] J. Lis, R. Pampuch, L. Stobierski, Int. J. Self-Propag. High-Temp. Synth., 1 (1992) 401.

[6] J. Lis, R. Pampuch, J. Piekarczyk, L. Stobierski, Ceram. Int., 19 (1993) 219.

[7] J. Lis, Y. Miyamoto, R. Pampuch, K. Tanihata, Mater. Lett., 22 (1995) 163-168.

[8] T. Goto, T. Hirai, Mater. Res. Bull., 22 (1987) 1195-1201.

[9] M.W. Barsoum, T. El-Raghy, J. Am. Ceram. Soc., 79 (1996) 1953-1956.

[10] M.W. Barsoum, T. El-Raghy, J. Mater. Synth. Process., 5 (1997) 197-216.

[11] M.W. Barsoum, T. El-Raghy, L. Ogbuji, J. Electrochem. Soc., 144 (1997) 2508-2516.

[12] T. El-Raghy, A. Zavaliangos, M.W. Barsoum, S.R. Kalidindi, J. Am. Ceram. Soc., 80 (1997) 513-516.

[13] M.W. Barsoum, T. El-Raghy, C. Rawn, W.D. Porter, J. Phys. Chem. Solids, 60 (1999) 429-439.

[14] M.W. Barsoum, T. El-Raghy, Metall. Mater. Trans. A, 30 (1999) 363-369.

[15] M.W. Barsoum, Prog. Solid State Chem., 28 (2000) 201-281.

[16] R. Radhakrishnan, J.J. Williams, M. Akinc, J. Alloy. Compd., 285 (1999) 85-88.

[17] M.W. Barsoum, T. El-Raghy, Am. Scientist, 89 (2001) 334-343.

[18] C.J. Gilbert, D.R. Bloyer, M.W. Barsoum, T. El-Raghy, A.P. Tomsia, R.O. Ritchie, Scr. Mater., 42 (2000) $761-767$.

[19] M.W. Barsoum, M. Radovic, P. Finkel, T. El-Raghy, Appl. Phys. Lett., 79 (2001) 479-481.

[20] M. Radovic, M.W. Barsoum, T. El-Raghy, J. Seidensticker, S. Wiederhorn, Acta Mater., 48 (2000) 453-459.

[21] T. El-Raghy, M.W. Barsoum, A. Zavaliangos, S.R. Kalidindi, J. Am. Ceram. Soc., 82 (1999) 2855-2860.

[22] N.F. Gao, Y. Miyamoto, D. Zhang, Mater. Lett., 55 (2002) 61-66.

[23] E.H. Kisi, J.A.A. Crossley, S. Myhra, M.W. Barsoum, J. Phys. Chem. Solids, 59 (1998) 1437-1443.

[24] V.D. Jovic, M.W. Barsoum, J. Electrochem. Soc., 151 (2004) B71-72.

[25] V.D. Jovic, B.M. Jovic, S. Gupta, T. El-Raghy, M.W. Barsoum, Corros. Sci., 48 (2006) 4274-4282.

[26] J. Travaglini, M.W. Barsoum, V.D. Jovic, T. El-Raghy, Corros. Sci., 45 (2003) 1313-1327.

[27] J.F. Ziegler, http://www.srim.org/.

[28] A. Audren, A. Benyagoub, L. Thomé, F. Garrido, Nucl. Instrum. Methods B, 257 (2007) 227-230.

[29] M. Beauvy, C. Dalmasso, C. Thiriet-Dodane, D. Simeone, D. Gosset, Nucl. Instrum. Methods B, 242 (2006) $557-$ 561 .

[30] K.R. Mavani, D.S. Rana, S. Rayaprol, R.N. Parmar, D.G. Kuberkar, R. Kumar, M. Tonouchi, J. John, R. Nagarajan, Solid State Commun., 142 (2007) 462-465.

[31] P.C. Srivastava, V. Ganesan, O.P. Sinha, Nucl. Instrum. Methods B, 187 (2002) 220-230.

[32] V.A. Skuratov, D.L. Zagorski, A.E. Efimov, V.A. Kluev, Y.P. Toporov, B.V. Mchedlishvili, Radiat. Meas., 34 (2001) 571-576.

[33] V.A. Skuratov, A.E. Efimov, K. Havancsak, Nucl. Instrum. Methods B, 250 (2006) 245-249.

[34] R.L. Dubey, S.K. Dubey, A.D. Yadav, S.J. Gupta, S.D. Pandey, T.K. Gundu Rao, T. Mohanty, D. Kanjilal, Nucl. Instrum. Methods B, 257 (2007) 287-292.

[35] S. Ghosh, V. Ganesan, S.A. Khan, P. Ayyub, N. Kumar, Appl. Surf. Sci., 252 (2006) 8223-8228.

[36] J.F. Carlotti, A.D. Touboul, M. Ramonda, M. Caussanel, C. Guasch, J. Bonnet, J. Gasiot, Appl. Phys. Lett., 88 (2006) 1-3.

[37] S. Rusponi, G. Costantini, C. Boragno, U. Valbusa, Phys. Rev. Lett., 81 (1998) 2735-2738.

[38] Y. Yamauchi, T. Taguchi, Y. Hirohata, T. Hino, M. Nishikawa, Vacuum, 74 (2004) 479-484.

[39] A.L. Stepanov, V.N. Popok, Surf. Sci., 566-568 (2004) 1250-1254. 